\title{
Urban Park Planning on Spatial Disparity between Demand and Supply of Park Service
}

\author{
Shaoli Liu \\ College of Geography and Remote Sensing, Nanjing University of Information Science and \\ Technology, China \\ ytliushaoli@163.com
}

\begin{abstract}
Keywords: supply-demand analysis, park service, spatial disparity, urban park planning
Abstract. Urban parks are one of the important parts of public infrastructure and have the function to improve residents quality of life, therefore, one of the primary issues in urban planning is to ensure to meet residents demands for the quantity and spatial distribution of parks. In many cities, some localities may suffer from insufficient supply because few applicable parks are located near in densely populated areas. Thus the focus of research is to determine the differences between demand for and supply of urban park services. As an effective method for measuring spatial planning of public facilities, accessibility assessment can help us to solve this problem. For this reason, spatial disparity between demand for and supply of urban park services are confirmed by calculating per capita park area within accessibility scope. This result is expected to aid urban planners in deciding where to prioritize the construction of parks, and also promotes more fair and reasonable allocation of public resources.
\end{abstract}

\section{Introduction}

Urban Parks are one of the important parts of public infrastructure and beneficial to city ecological environments, including air quality improvement and effective absorption of $\mathrm{CO}_{2}$, the main cause of global warming [1,2]. Meanwhile, they are ideal places for residents leisure activities that promote emotional stability and improved quality of life [3]. For this reason, more attention is paid to urban parks planning, which focus on urban residents whether they can conveniently and equal enjoyment of all functions and services provided by parks, namely accessibility and equality of urban park services.

Accessibility is a very important factor of urban park planning that can be used to assess service levels of urban parks [4,5]. Accessibility to urban parks is adequate when the spatial distribution of population is in harmony with parks' $[6,7,8]$, that is, whether densely or sparsely populated areas in city, residents demands can be satisfied with suitable parks provision. On the contrary, accessibility is inadequate when supply of park services can not meet residents needs. Accessibility is further applied to estimate the differences of park service among various socio-economic groups, which reflect the degree of fairness and equality for park services providing to different groups $[9,10]$.

The spatial disparity of supply and demand is highlighted a critical factor in evaluating of urban parks spatial planning. The places where supply is not proportional to demand should be concerned by planner. The purpose of this study is to propose the concept of per capita park area as an assessment index to denote the places of undersupply or excessive demand of park services and the definition of park shortage area as an evaluation indicator to ascertain the priority of parks construction at a regional scale. In section 2, the concept of two indices used in this study is explained in detail. The proposed indices are empirically applied into Nanjing, and in the context of interpreting the analytical results, the impact of planning is discribed in section 3. At the final section, some limitations of this study are discussed and ideas for further studies are suggested.

\section{Methodology}

In this paper, spatial disparity of park service availability is represented by the level of per capita park area within the scope of park radius. Regions where demand exceeds supply judging by standards of per capita park area in related legislations are highly-focused in planning. Spatial differentiation of 
supply of and demand for park service is denoted by shortage area. The definition of indices shows as follows:

$$
\begin{aligned}
& A P=\sum_{i=1}^{3} A_{p i}, A_{p i}=\sum_{j=1}^{n} \frac{G A_{j}}{S P_{j}} \\
& G A_{g}=\left(N_{P}-A_{P}\right) \times P
\end{aligned}
$$

In Eq. $1, A_{P i}$ is the per capita park area and $A_{P}$ is the cumulative value of $A_{P i}$ for three catigories of parks defined in this paper. The parameter $G A_{j}$ and $S P_{j}$ refer to the park area and population which enjoy services within park radius in $j$, respectively. The park radius is calculated by total lengths of urban roads that residents travel from their residence to parks. Residents can enjoy park service within the radius, but not be provided when they are outer the radius. The location of large parks $(\geq 10.0$ ha $)$ is represented by their entries, and residents enjoy park services when they reach entry near by their localities. Thus each park is expressed by entry set, this is a basis of summarizing the number of population who can possess park service. The location of small parks $(<10.0 \mathrm{ha})$ is indicated by its' geometric centroid. In Eq. 2, $G A_{g}$ shows shortage area of park which indicates the degree of demand for parks, and $P$ represents population number of the region. $N_{P}$ denotes the standard of per capita park area, and $6 \mathrm{~m}^{2}$ is determined as a lower limit of per capita park area in this study, referring to "the regulation of construction indicators for urban greening planning" and "the standard of national ecological garden city" [11].

\section{Case study}

We chose Nanjing, the capital of Jiangsu which is one of important provinces in China's coastal region, for an empirical application of the proposed analytic methodology. With a population of 7.17 million (2010) and densely populated area locating in city center, Nanjing consists of 8 districts which include 49 streets, and furtherly, street is sub-unit of district. Xinjiekou central business district (CBD) is located at the junction of Gulou, Xuanwu and Baixia. Provincial Government locates in Gulou and Xiaguan to the north, Jianye and Yuhua to the south. Municipal Government lies in Xuanwu and Qixia to the north, Baixia and Qinhuai to the south. Fig. 1 shows the spatial distribution of population density in Nanjing, with "dot density" indicating the density of population. The greater the dot density is, the higher the population density gets. Each point indicates 3,000 person, that is to say, if there is 10 points in a street, it's population is 30,000 person. The point density around Xinjiekou CBD is more intensive than that of other regions, and so it is the most densely populated area in Nanjing. In addition, the population density of Hunan Road sub-business district is also very high, which locates in the middle of Gulou district and west of Xuanwu lake. With increasing distance from the central business district, the population density is decreased rapidly. The maximum of population density within Baixia district is up to 54,359 person in one square kilometer, which is the core area of Xinjiekou CBD. But the minimum is down to 1,050 person belonging to Qixia district, near the outer boundary of study region.

Service level is mainly determined by park size and service radius. In virtue of these two indicators and national relative standards, as well as the distribution of parks in Nanjing shown in Fig. 2, parks are divided into three categories (Table 1). As of 2010, Nanjing has 167 parks with area more than 1.0 ha. The key to adequate supply of parks is that Xuanwu has two city-wide parks with area over 100.0 ha providing service for total residents. Gulou and Xiaguan possess more regional parks, Jianye owns a number of community parks, but Qinhuai and Baixia have a few parks both in quantity and size, which lead to the overall shortage of supply. The statistical results of park service level in district scale are shown in Table 2. Districts where the city-wide parks locate in is higher in per capita park area. The reason of regions in low per capita park area lies in two aspects, one is insufficient supply of parks in densely populated area; the other is unreasonable spatial distribution of parks in sparsely populated area. The regions with larger shortage of park services are mainly around Xinjiekou CBD and Hunan Road sub-business district, as well as the old town of Gulou, Jianye and Qinhuai. 
Table 1 Park categories of Nanjing

\begin{tabular}{cccc}
\hline Category & City-wide park & Regional park & Community park \\
Parameter & $\geq 100.0 \mathrm{ha}$ & $10.0-100.0 \mathrm{ha}$ & $1.0-10.0 \mathrm{ha}$ \\
Area & $5.0 \mathrm{~km}$ & $2.0 \mathrm{~km}$ & $0.5 \mathrm{~km}$ \\
Radius & 5 & 28 & 134 \\
Number & &
\end{tabular}

Table 2 Statistics of park service level in districts in Nanjing

\begin{tabular}{cccccc}
\hline Index & $\begin{array}{c}\text { Land area } \\
{\left[\mathrm{km}^{2}\right]}\end{array}$ & $\begin{array}{c}\text { Population density } \\
{\left[\mathrm{cap} / \mathrm{km}^{2}\right]}\end{array}$ & $\begin{array}{c}\text { Park area } \\
{\left[\mathrm{km}^{2}\right]}\end{array}$ & $\begin{array}{c}\text { Per capita park } \\
\text { area [mcap] }\end{array}$ & $\begin{array}{c}\text { Park shortage } \\
\text { area [ha] }\end{array}$ \\
\hline Baixia & 20.91 & 27120.99 & 0.32 & 0.56 & 86.80 \\
Gulou & 25.48 & 32421.51 & 1.55 & 1.88 & 176.18 \\
Jianye & 30.40 & 12075.66 & 2.80 & 7.63 & 61.41 \\
Qixia & 36.32 & 6431.72 & 3.59 & 15.37 & 3.93 \\
Qinhuai & 20.59 & 18873.24 & 0.77 & 1.98 & 128.20 \\
Xiaguan & 23.09 & 19276.74 & 3.51 & 7.89 & 21.29 \\
Xuanwu & 65.93 & 9340.21 & 28.43 & 46.17 & 0.51 \\
Yuhua & 20.40 & 7500.00 & 2.29 & 14.97 & 12.70 \\
Total & 243.12 & 14792.69 & 43.26 & 12.03 & 491.02 \\
\hline
\end{tabular}

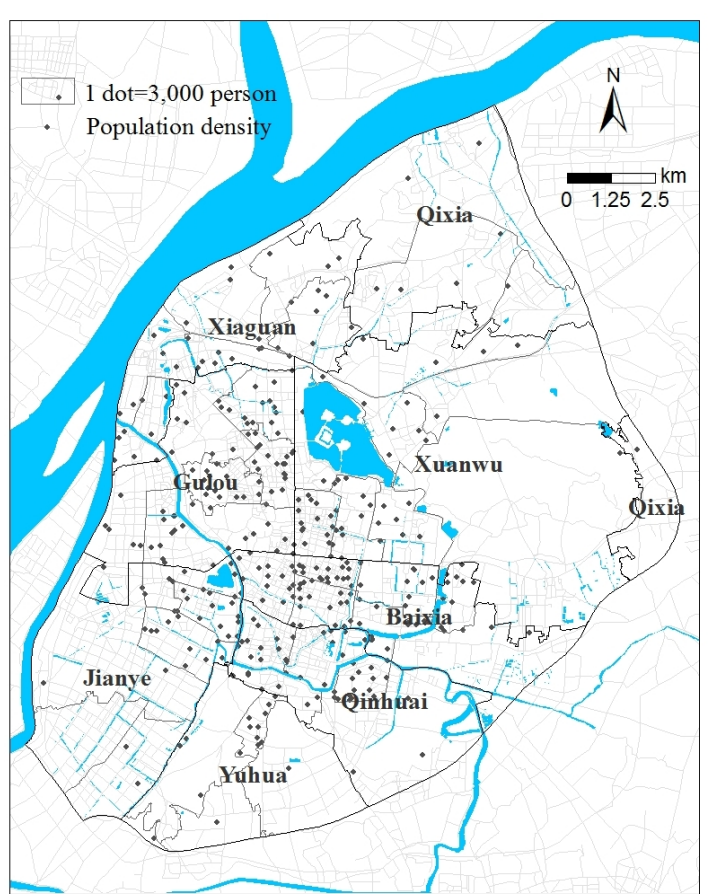

Fig. 1 Distribution of population density in Nanjing

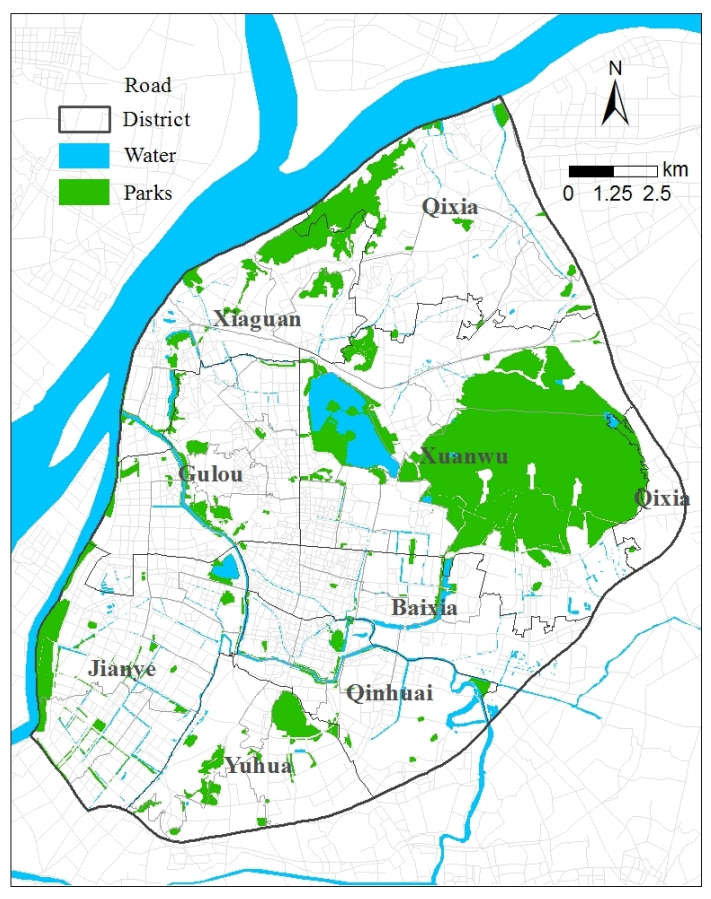

Fig. 2 Distribution of parks in Nanjing

Fig. 3 illustrates the spatial disparity of park service after applying Eq. 1 to every parks, which helps us to define adequate and inadequate park services. Places with high per capita park area in dark color appear near by city-wide parks and/or regional and community parks with sufficient supply. By comparison, spots with low per capita park area in light color mainly locate around central business districts with densely populated area, old town with few parks and regions near outer boundary with sparsely populated area. Therefore, these areas are faced with serious supply deficiency of park service. Further analysis of park service in districts shows that Xuanwu is adequate due to 2 parks with area more than 100.0 ha, Gulou is generally inadquate mainly because of excessive population provided by regional and community Parks which size are far less than city-wide parks, and Qinhuai has largely insufficiency on account of the shortage of parks quantity. The maximal value of high per capita park area is 98.96 , but the minimum is 0 , which means huge discrepancy in the level of park service in 
different areas. Inadequate places of park services that are represented with light color in Fig. 3 should be given priority by urban planning workers.

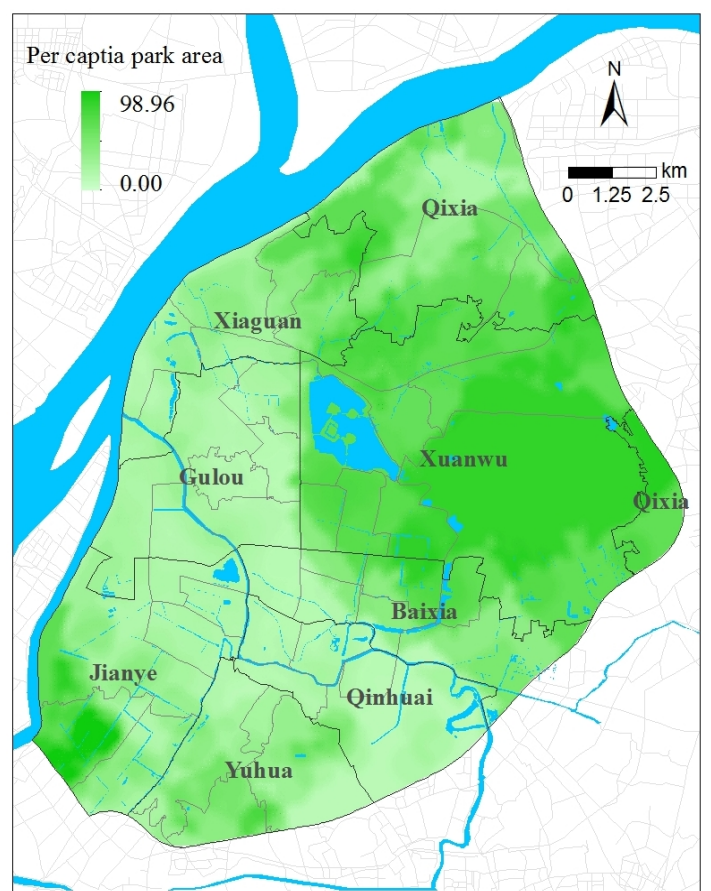

Fig. 3 Disparity of per capita park area in Nanjing

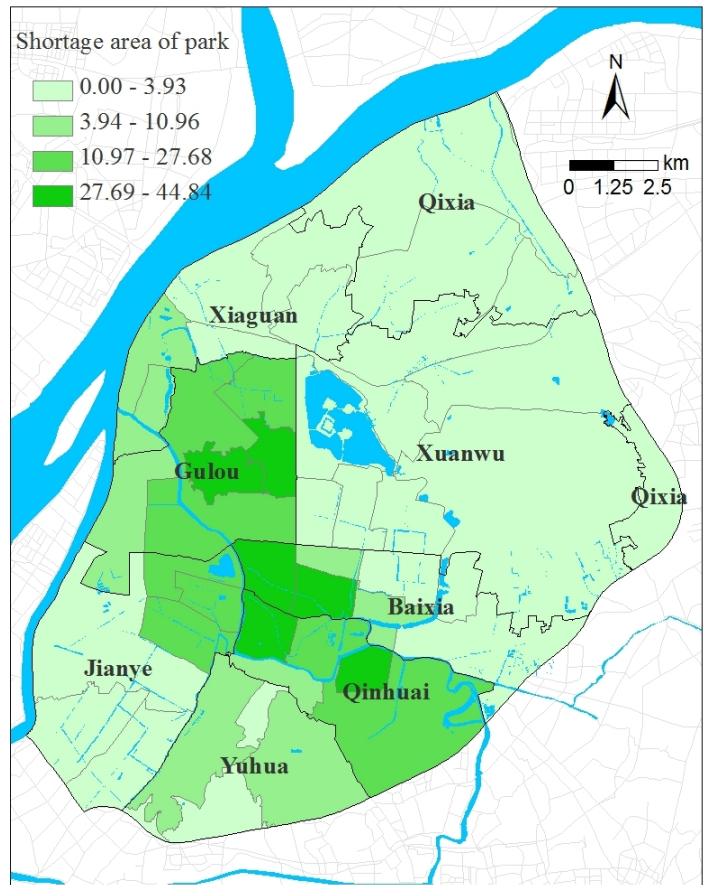

Fig. 4 Differentiation of shortage area of park in Nanjing

Results by Eq. 2 are conductive to make certain the degree of shortage of park service in Nanjing. According to the brightness of color and caculated values, streets with serious shortage of park supply could be found very easily in Fig. 4, combined with Fig. 3 the specific sites with insufficient supply of park could more clearly for us. It is totally unnecessary to consider those areas which have adequate park services. There are 3 districts in large deficiency of demand for parks, and Gulou has the largest deficiency among them summed up to 176.18 ha, followed by Qinhuai and Jianye. Xuanwu has the smallest deficiency with shortage area only 0.51 ha. In order to make more population enjoy park services and to narrow the gap between supply of and demand for parks among streets, planners should first consider the area with larger differences between demand and supply during park construction. From another perspective, regions with seriously insufficiency of park service still mainly locate in the densely populated area in the neighborhood of Xinjiekou CBD and Hunan Road sub-business center. In other words, excessive demands for parks cause the contradiction between supply and demand. But these two areas have not enough lands to construct parks, the situation of inadequate park supply will persist for a long time. The better solution is to build new parks in suitable sites and increase supply of parks, combining with reconstruction of old town. Or guiding portion of population migrate to those areas with adequate park services, that contributes to improve the status of insufficient supply by reducing population needs. Meanwhile, building new parks at the right places could be carried out in other regions confronting the circumstance of insufficient supply, and the discrepance of supply and demand is solved by increasing parks supply.

\section{Conclusions}

The disparity of supply and demand in a specific area may be determined by considering parks supply and residents demand. With respect to the level of available service in parks, the obvious contradiction between supply and demand in region is mainly present in densely populated areas on the results of case study. Thus, the level of parks in harmony with population in spatial distribution may be more critical factor that affects the extent of parks supply. City planners should give priority to those places where residents demand is far greater than parks supply when building new parks, rather than just consider 
whether there are many parks nearby, because residents in areas where population density is high may suffer from lack of services even though many parks are located nearby.

For the sake of more rational planning of urban parks, spatial disparity between demand and supply is applied to measure the level of park services in this paper. Thus suggestions are provided for urban planning by comparing the extent of shortage area of park. The areas with sufficient and insufficient supply of parks could understand intuitively from figure in virtue of method mentioned in the above. City planners can get the specific situation of shortage in park supply though the parameters of per capita in each point. In the mean time, the results can be further extended according to the standards of regulations about per capita of park service so that planners may determine the order and scale of parks construction by means of calculating the degree of difference between supply and demand. And finally, the method mentioned in this study can also provide some helps for the planning and construction of other public facilities in city.

There are some limitations in this paper. Service radius of park is determined by it's size, but the attractiveness of park in different sizes to residents is not considered. Next, using inside and outside the boundary of park service to determine whether park providing services or not, will lead to spatial discontinuity of park services. Then, the way simplifying residents behavioral characteristics also make certain deviation between results and actual behavior. These aspects need to improve in future studies.

\section{Acknowledgements}

This paper was supported by the project "Natural Science Foundation for Universities in Jiangsu Province" with number 15KJB170011.

\section{References}

[1] Chiesura A., The role of urban parks for the sustainable city, Landscape and Urban Planning, 68(1) (2004) 129-138.

[2] Boone, C.G., Buckley, G.L., Grove, J.M., Sister, C., Parks and people: An environmental justice inquiry in Baltimore, MD, Annals of the Association of American Geographers, 99(4) (2009) 767-787.

[3] G. Lee, I. Hong, Measuring spatial accessibility in the context of spatial disparity between demand and supply of urban park service, Landscape and Urban Planning, 119(8) (2013) 85-90.

[4] Lindsey, G., Maraj, M., Kuan, S., Access, equity, and urban greenways: An exploratory investigation, Professional Geographer, 53(3) (2001) 332-346.

[5] Nicholls S., Measuring the accessibility and equity of public parks: a case study using GIS, Managing Leisure, 6(4) (2001) 201-219.

[6] Talen, E., Anselin, L., Assessing spatial equity: An evaluation of measures of accessibility to public playgrounds, Environment and Planning A, 30 (1998) 595-613.

[7] Wolch, J., Wilson, J.P., Fehrenbach, J. , Parks and park funding in Los Angeles: An equity-mapping analysis, Urban Geography, 26 (2005) 4-35.

[8] Oh K., Jeong S., Assessing the spatial distribution of urban parks using GIS, Landscape and Urban Planning, 82(12) (2007) 25-32.

[9] Comber A., Brunsdon C., Green E., Using a GIS-based network analysis to determine urban greenspace accessibility for different ethnic and religious groups, Landscape and Urban Planning, 86(1) (2008) 103-114.

[10] Dajun Dai, Racial/ethnic and socio-economic disparities in urban green space accessibility: Where to intervene? Landscape and Urban Planning, 102(6) (2011) 234-244.

[11] Kunpeng Gui, Jiangang Xu, Xiang Zhang, Optimization of urban green space spatial arrangement based on supply- demand analysis: a case study in Nanjing city, China, Chinese Journal of Applied Ecology, 24(5) (2013) 1215-1223. In Chinese 